\title{
The antidepressant debate
}

\author{
JOANNA MONCRIEFF
}

There has been an extensive debate recently in the North American medical literature and general press concerning the efficacy of antidepressant drugs. Little of this has reached the European press. Andrews' editorial (Andrews, 2001) is a welcome contribution but focuses only on the reasons for and repercussions of the large placebo response in depression. Other reviews critical of antidepressant research have pointed out the numerous methodological problems involved, the inconsistency of the literature and the lack of evidence that the escalation in prescribing of antidepressants has had any impact on the burden of depressive illness (Greenberg \& Fisher, 1997; Antonuccio et al, 1999; Moncrieff, 2001). From this perspective the question of the efficacy of antidepressants remains unresolved. On the other side of the debate, Quitkin et al (2000) have responded to some of these criticisms and tried to allay doubts about the efficacy of these drugs.

\section{METHODOLOGICAL PROBLEMS}

The issue of 'unblinding' or the 'amplified placebo effect' (Thomson, 1982) has been raised periodically since the 1960s. The suggestion is that a whole or part of the superiority shown by antidepressants over placebo is attributable to the non-specific effects of taking an active medication as opposed to an inert one, in a context in which there are usually high expectations of active treatment. Greenberg et al (1994) showed that effect size correlated with incidence of side-effects in trials of fluoxetine. They also found that the effects of older antidepressants compared with placebo were less than the effects of newer ones in a meta-analysis of three-arm trials comparing a new antidepressant and an old one with placebo (Greenberg et al,
1992). They suggested that this was due to reduced expectations of the performance of the older antidepressants. Moncrieff $e t a l$ (1998) found lower effect sizes in trials using active placebos. Quitkin et al (2000) challenged the importance of 'unblinding'. They failed to replicate the findings of the meta-analysis of three-arm trials using categorical outcomes rather than continuous ones. However, use of categorical outcomes may in itself inflate drug-placebo differences (Moncrieff, 2001). Quitkin et al also criticised the findings from active placebo-controlled trials on the basis that drug improvement rates were lower than expected.

Other criticisms of antidepressant trials have included the validity of measurement techniques. The Hamilton Rating Scale for Depression (Hamilton, 1960) has been criticised because it contains a large number of items relating to sleep and anxiety, which is likely to favour any active drug with sedative properties (Murray, 1989). Other scales have been developed explicitly to maximise drug-placebo differences in randomised trials (Montgomery \& Åsberg, 1979). Selective reporting of outcomes is a potential problem, as it may be in other areas, and use of categorical outcomes may inflate drug-placebo differences if results are clustered around the point of division of categories (Moncrieff, 2001). The use of a placebo wash-out period has been examined by Antonuccio et al (1999), who concluded that it did not necessarily bias trials against placebos. Failure to perform 'intention to treat' analysis has been shown to inflate apparent treatment effects in antidepressant trials (Bollini et al, 1999). Publication bias is also a concern (Antonuccio et al, 1999; Moncrieff, 2001) and a recent meta-analysis showed that sponsorship was the strongest predictor of outcome in comparative trials with selective serotonin reuptake inhibitors (Freemantle $e t$ al, 2000).

\section{INDIVIDUAL STUDIES}

There are now so many randomised, controlled trials of antidepressants compared with placebos that having a full grasp of the original evidence is almost impossible for the ordinary clinician or researcher. It is agreed that there is great heterogeneity among such trials of antidepressants, with a substantial proportion finding no difference between drug and placebo. Morris \& Beck (1974) found that around a third of trials of tricyclic antidepressants were negative. Rogers \& Clay (1975) found that $64 \%$ of trials of imipramine were negative, and McNair (1974) found that $81 \%$ of comparisons using subjective outcomes were negative. Some large and influential individual studies were essentially negative. The Medical Research Council trial found no difference between imipramine and placebo on the main categorical outcome and negligible differences in individual symptoms (Medical Research Council, 1965). The overall difference on the symptom-based scale was not reported. The second National Institute of Mental Health collaborative depression study of 714 patients with depression randomised to imipramine, chlorpromazine or placebo found small and inconsistent effects. Although it was reported that imipramine was superior to placebo at 3 weeks, there was no difference at the end of the 5-week treatment period or at the end of followup. In addition, the main report on efficacy excluded the 159 Black patients who were said to have shown a poorer response to imipramine (Raskin et al, 1970).

Recent studies are almost all conducted with out-patients and most are sponsored by the pharmaceutical industry. It is possible that there is a greater potential for placebo effects and therefore for amplified placebo effects in people with milder disorders. However, so few studies test the integrity of the double-masking that it is difficult to know to what extent this is the case (Even et al, 2000).

\section{SPECIFICITYOF ANTIDEPRESSANTS}

Many substances not conventionally classified as antidepressants have been found to be superior to placebo or to have equivalent efficacy to antidepressants in trials of treatment of depression. The list includes various neuroleptics (Robertson \& Trimble, 1982), barbiturates (Blashki et al, 1971), 
benzodiazepines (Imlah, 1985), buspirone (Robinson et al, 1990), some stimulants (Rickels et al, 1970) and more recently Hypericum extract (Philipp et al, 1999). These observations might imply that depression is susceptible to a variety of non-disease-specific pharmacological actions such as sedation or psychostimulation, as well as the effects of suggestion. These effects may account for at least part of the impact of conventionally classified antidepressants. However, it has also been suggested that some of these other substances themselves possess specific antidepressant activity (Robertson \& Trimble, 1982). It is difficult to know how this issue can be resolved. If anything that affects the outcome of depression is classified as an antidepressant, it becomes impossible to extricate specific from non-specific effects.

Although there is an assumption that antidepressants act specifically on some biochemical pathway involved in the pathogenesis of depression, there is no consistent account of what this might consist of. Evidence from trials shows that no particular pharmacological action can be shown to be superior to another (Freemantle et al, 2000). The fact that depressive conditions respond to a variety of psychotherapies also implies that recovery is not achieved through a particular biochemical manipulation.

\section{ETHICS AND ADVERSE EFFECTS}

Absolute certainty about the efficacy of antidepressants, or any other treatment, is impossible. The importance we attach to doubts that can be raised about the existing evidence depends partly on the perceived consequences of using a treatment that might yet prove to be ineffective. Adverse physical effects of antidepressant treatment are well known, but the psychological effects are rarely discussed. The prescription of medication for depression conveys the powerful message that we are passive victims of our biology. The consequences for the individual may include a failure to develop intrinsic coping strategies, leading to psychological dependence on drug treatment and increased susceptibility to recurrence. At the social level the effects may contribute to the tendency towards increasing perception of ill health and recourse to medical intervention (Barsky \& Borus,

JOANNA MONCRIEFF, MRCPsych, University College London, Department of Psychiatry and Behavioural Sciences, Holborn Union Building, Archway Campus, London NI9 5LW, UK

(First received I3 March 200I, accepted 22 June 200I)

1995). The pharmaceutical industry is an obvious beneficiary of this situation and psychiatry must be wary of being swept along by this juggernaut. In order to achieve a truly balanced view of the evidence it is necessary at least to raise questions about the efficacy of antidepressants.

\section{DECLARATION OF INTEREST}

None.

\section{REFERENCES}

Andrews, G. (200I) Placebo response in depression: bane of research, boon to therapy. British Journal of Psychiatry, 178, 192-194

Antonuccio, D. O., Danton, W. V., DeNelsky, G.Y., et al (1999) Raising questions about antidepressants. Psychotherapy and Psychosomatics, 68, 3-14.

Barsky, A. J. \& Borus, J. F. (1995) Somatization and medicalization in the era of managed care. JAMA, $\mathbf{2 7 4}$ 1931-1934.

Blashki, T. G., Mowbray, R. \& Davies, B. (197I) Controlled trial of amitriptyline in general practice. $B M$ J i, 133-138

Bollini, P., Pampallona, S., Tibaldi, G., et al (1999) Effectiveness of antidepressants. Meta-analysis of doseeffect relationships in randomised clinical trials. British Journal of Psychiatry, 174, 297-303.

Even, C., Siobud-Dorocant, E. \& Dardennes, R. M. (2000) Critical approach to antidepressant trials. Blindness protection is necessary, feasible and measurable. British Journal of Psychiatry, 177, 47-51.

Freemantle, N., Anderson, I. M. \& Young, P. (2000) Predictive value of pharmacological activity for the relative efficacy of antidepressant drugs. Metaregression analysis. British Journal of Psychiatry, 177, 292-302.

Greenberg, R. P., Bornstein, R. F., Greenberg, M. D. et al (1992) A meta-analysis of antidepressant outcome under 'blinder' conditions. Journal of Consulting and Clinical Psychology, 60, 664-669.

_, _ , Zborowski, M. J., et al (1994) A meta-analysis of fluoxetine outcome in the treatment of depression. Journal of Nervous and Mental Disease, I82, 547-55I.

— \& Fisher, S. (1997) Mood mending medicines: probing drug, psychotherapy and placebo solutions. In From Placebo to Panacea: Putting Psychiatric Drugs to the Test (eds R. P. Greenberg \& S. Fisher), pp. I15-172. New York: John Wiley \& Sons.

Hamilton, M. (1960) A rating scale for depression. Journal of Neurology, Neurosurgery and Psychiatry, 23. $56-62$
Imlah, N.W. (1985) An evaluation of alprazolam in the treatment of reactive or neurotic (secondary) depression. British Journal of Psychiatry, 146, 515-5I9.

McNair, D. M. (1974) Self-evaluations of antidepressants. Psychopharmacologia, 37, 28I-302.

Medical Research Council (1965) Clinical trial of the treatment of depressive illness. BMJ, i, 88I-886.

Moncrieff, J., Wessely, S. \& Hardy, R. (1998) Metaanalysis of trials comparing antidepressants with active placebos. British Journal of Psychiatry, I72, 227-231.

- (200I) Are antidepressants over-rated? A review of methodological problems in antidepressant trials. Journal of Nervous and Mental Disease, 189, 288-295.

Montgomery, S. A. \& Åsberg, M. (1979) A new depression scale designed to be sensitive to change. British Journal of Psychiatry, 134, 382-389.

Morris, J. B. \& Beck, A.T. (1974) The efficacy of antidepressant drugs. A review of research (1958 to 1972). Archives of General Psychiatry, 30, 667-674.

Murray, E. J. (1989) Measurement issues in the evaluation of psychopharmacological therapy. In The Limits of Biological Treatments for Psychological Distress (eds S. Fisher \& R. P. Greenberg), pp. 39-68. Hillsdale, NJ: Lawrence Erlbaum.

Philipp, M., Kohnen, R. \& Hiller, K. P. (1999) Hypericum extract versus imipramine or placebo in patients with moderate depression: randomised multicentre study of treatment for eight weeks. BMJ, 319, 1534-1538.

Quitkin, F. M., Rabkin, J. G., Gerald, J., et al (2000) Validity of clinical trials of antidepressants. American Journal of Psychiatry, 157, 327-337.

Raskin, A., Schulterbrandt, J. G., Reatig, N., et al (1970) Differential response to chlorpromazine, imipramine and placebo. Archives of General Psychiatry, 23, 164-173.

Rickels, K., Gordon, P. E., Gansman, D. H., et al (1970) Pemoline and methylphenidate in mildly depressed outpatients. Clinical Pharmacology and Therapeutics, II, 698-710.

Robertson, M. M. \& Trimble, M. R. (1982) Major tranquillisers used as antidepressants. A review. Journal of Affective Disorders, 4, 173-193.

Robinson, D. S., Rickels, K., Feighner, J., et al (1990) Clinical effects of 5-HTIA partial agonists in depression: a composite analysis of buspirone in the treatment of depression. Journal of Clinical Psychopharmacology, 10 (suppl. 3), 67S-76S

Rogers, S. C. \& Clay, P. M. (1975) A statistical review of controlled trials of imipramine and placebo in the treatment of depressive illness. British Journal of Psychiatry, 127, 599-603.

Thomson, R. (1982) Side effects and placebo amplification. British Journal of Psychiatry, 140, 64-68. 